Department of Economics and Marketing

Discussion Paper No.35

\title{
Morally We Roll Along: \\ (Optimistic Reflections) \\ On Moral Progress
}

Stan Godlovich

September 1997

International Trade Policy Research Centre

Department of Economics and Marketing

PO Box 84

Lincoln University

CANTERBURY

Telephone No: (64) (3) 3252811

Fax No: (64) (3) 3253847

ISSN 1173-0854

ISBN 1-877176-12-5 
It is evident that we are at a primitive stage of moral development. Even the most civilised human beings have only a haphazard understanding of how to live, how to treat others, how to organise their societies. The idea that the basic principles of morality are known , and that the problems all come in their interpretation and application, is one of the most fantastic conceits to which our conceited species has been drawn. (The idea that if we cannot easily know it, there is no truth here is no less conceited.) Not all of our ignorance in these areas is ethical, but a lot of it is. And the idea of the possibility of moral progress is an essential condition of moral progress. None of it is inevitable. ${ }^{1}$

Thomas Nagel

Stan Godlovitch is a Senior Lecturer in philosophy in the Department of Human and Leisure Sciences at Lincoln University.

\footnotetext{
${ }^{1}$ Thomas Nagel, The View from Nowhere (New York: Oxford UP), p. 186
} 


\section{Contents}

1. Some Themes and Undercurrents 2

1.1 Moral Domains and Moral Authority 3

1.2 Freedom and Knowledge 4

1.3 Reflective Moralism 6

2. Varieties of Progress 7

2.1 Measuring Progress 7

2.2 Neutral Progress 8

2.3 Teleological Progress 8

$\begin{array}{ll}2.4 & \text { Improvement or Ameliorative Progress } \\ \end{array}$

3. Progress Hierarchically Conceived 12

3.1 The Relativity of Progress 12

3.2 Internal and External Progress 14

4. Taking Stock 17

4.1 Where All This is Tending 19 


\section{A Joke from Jake and Elwood}

In one of the many matchless scenes in John Landis's 1980 classic The Blues Brothers, Jake and Elwood invade a swank Chicago restaurant, seat themselves at a table next to a very proper, very patrician family, and proceed to conduct themselves in an exuberantly obnoxious manner. Such behaviour predictably upsets the family members who try without success to ignore their unmannerly neighbours. Taking full advantage of his assault advantage, Jake leans over and greasily addresses the family patriarch in a gruff all-purpose foreign accent. Gesturing grandly at the man's wife and daughters, Jake puts it to him man-to-man:"Your women. I want your women. How much for your women?"

The humour in the scene flows not only from the comic genius of John Belushi and his take on the well-worn incongruities of the boorish slob amongst the genteel, but from one of those tacit absurdities which the scene brings into centre stage. You just don't horse-trade in women. In fact, you just don't buy and sell humans, period. They are just not that sort of thing - and not just among civilised folk.

Had Jake been out to horse-trade in horses, the absurdity which infects the original scene would have been lost. More interestingly, however, had the movie screened at a time - not so long ago - when just that sort of horse-trading in humans was just another piece of business as usual, another brisk market exchange, so too the intended absurdity would simply have flopped. At least, the commercial aspect of the scene would not have contributed to its humour.

At the risk of sounding ponderous, the scene from the Blues Brothers works now as black humour because the typical contemporary Western audience can reliably be counted upon as subscribing to an unquestioned, categorical, absolute, strictly moral conviction. Human beings are not marketable commodities. It goes even further. We don't allow others, even if they volunteer, to sell themselves into slavery. I cannot buy another human as my property, nor can you voluntarily and without coercion sell your person to me as an item of fair exchange. We can sell our services, to be sure, our time, our blood, our labour, our skills, but we cannot sell ourselves. I cannot own you, and you cannot own me, period. It wasn't always this way, as becomes disorientingly clear when one encounters and even admires a rather handsome 18th century stone building near the heart of Charleston, South Carolina - the former slave auction centre. 
What accounts for this change? One serious explanation as to why we don't now trade in fellow humans must rest in part, if not exclusively, on appeal to the strength of moral principles. Taken together, these conditions - the former commonplace of the slave trade and the present commonplace of Jake and Elwood's joke - signal a phenomenon we might as well call moral progress. We seem to have moved on morally, and for the better. That we will continue thus is at least a reasonable desire.

\section{Some Themes and Undercurrents}

A number of themes are addressed below concerning the environment, nature, and implications of moral progress. Central to the account is the very credibility of moral progress itself, for we cannot suppose moral progress to have taken place without understanding what exactly it is. To get clear about this notion, some groundclearing is necessary. This concerns various general concepts of progress, some relevant and some not, which need sorting out. We must also consider, however briefly, other domains in which progress of the relevant sort seems to have taken place as well as domains where the notion of progress is more controversial. So, for example, whereas it seems reasonably unproblematic to argue that progress has occurred in natural science and technology, it is far less certain that progress has taken place in art or religion. If talk about moral progress makes any sense, it seems to fall amongst such practices as law and government. The question arises: if there is moral (or legal or political) progress at all, are we right in characterising it in terms of the progress typical of the sciences? If not, may there be another way of characterising it which preserves its progressive quality?

Once we have to hand a working notion of moral progress, we must then turn to its implications for conduct. Morality is the name we give to a special body of rules, principles and notions which we identify as governing certain aspects of our conduct towards others. Those rules, principles and notions affect us both negatively and positively. They constrain our conduct toward others in various ways and thus define the limits of permissible action. They also oblige us to act benevolently on behalf of others. All this is done in the context of the moral regard or respect owed to others. Typical principles deal with, say, causing harm to others, or relate to practices such as promising, charitableness, fairness and truth-telling. Relatedly, we recognize morally relevant aspects of character - virtues and vices - such as honesty, generosity, duplicity, intolerance and so on, which, as exemplars, identify both worthy and destructive personality types. 


\subsection{Moral Domains and Moral Authority}

To understand fully the implications of any given morality, we must be aware not only of the rules, principles and notions appealed to, but, equally, of the domain to which those rules and principles properly apply. Who counts morally? Who are the proper beneficiaries of morally sanctioned and required conduct? If, as seems prima facie plausible, moral progress consists in the tendency towards a strengthening acknowledgment of the autonomy and moral status of an ever-expanding group; i.e. a growing moral inclusiveness, then what is permissible becomes proportionately more limited and what is obligatory increasingly more varied and demanding. The greater the limits on permissibility and the greater the broadening of obligation, the greater the likelihood of conflict with other dimensions of conduct, most pointedly those concerning our tendency to serve ourselves both individually and collectively in the name of rational prudence or self-interest. The greater the risk of conflict, the greater the need to establish the relative authority and stringency of the moral domain. To what extent do we allow our moral considerations to limit if not outrightly trump our non-moral interests? To what degree are we bound by the dictates of our morality? The question of authority has obviously both personal and collective dimensions. To the extent that we collectively abide by and even internalise a given moral injunction - e.g. "Thou shalt not buy and sell human beings” - such that we intend it to apply categorically, thereby have we vested in such an injunction as close to an absolute moral authority as we might recognize.

Given this sort of authority, one may enrich our first passing sketch of moral progress thus: if there is any moral progress at all, one makes moral progress to the extent that one vests increasingly greater moral authority in the rules and principles which are respectful of increasing moral inclusiveness. Note, this enrichment now incorporates two separable dimensions of moral progress; viz., the growth of the moral domain and the growth of moral authority. Growth in either might constitute a species of moral progress all on its own, though it seems fair to say that domain growth without authority growth is limp, while authority growth without domain growth arbitrarily plays favourites. The two dimensions share one telling feature; they both, in their own ways, magnify moral presence by limiting choice and action. Domain growth makes more choices and actions morally wrong by increasing the number of obligations we accept; while authority growth makes existing moral obligations more stringent and leaves less room open for excusable, unreflective, self-serving routines and preferences. If progress has indeed been made in the scope of the moral domain and if that 
growth is likely to continue, we can reasonably predict that what we collectively regard as the sphere of uncontestably permissible conduct will shrink. Given an accompanying progress in moral authority, what actions we actually will perform will be characterised increasingly in terms of their moral tone. In familiar terms, moral progress increasingly demands that an evergreater proportion of our actions be seen as "matters of principle”; i.e. as matters to be squared with the court of right and wrong.

\subsection{Freedom and Knowledge}

Underlying the account of moral progress are two major historical undercurrents, both of which flow from particularly Western aspects of philosophy and natural science, and which have increasingly influenced the transformation of our moral and political environments. One force has moved us ever closer to the realisation of both personal liberty and autonomy as well as collective sovereignty and self-determination. The other force, care of the dazzling growth in the natural sciences, has moved us ever closer to a more detached and objective understanding of our place in the grand historical and physical scheme of things.

On the philosophical side, we are heirs to a long-standing and successful liberationist and liberalising intellectual tradition which features among its most influential first voices the 17th century theorists John Locke and Thomas Hobbes. The theme of individual autonomy and collective sovereignty, strongly reinforced in the works of Voltaire, Rousseau and Jefferson, was woven into powerful political forces in the 18th century which precipitated the revolutions in the United States and France. Distilling that century's reflective sanctification of human autonomy and self-determination was the work of Kant. Upon this foundation, the liberal individualism of Bentham and Mill could confidently be built, as well as could the liberationist utopian themes of the early socialists and Marx. What began in a privileged climate of intellectual inquiry has become entrenched and internalised in the general populace, and became no longer a matter of opinion or controversy. We now live in a moral atmosphere in which many, perhaps most, take comfortably and intuitively for granted both the individual entitlement to live one's life as each one sees fit, and the collective entitlement to determine how we as a society are to be governed. How to resolve the tensions between these entitlements and to give each its proper due constitute two of the main moral and political issues of our time. That the tension exists at all is testimony to the categorical authority we 
vest in such entitlements. That it has taken nearly three centuries to flow freely in our veins is testimony to the persistence of ideas and to the resistance against them.

On the side of science, we are just beginning to absorb the full implications of the story Darwin and Wallace first told in the mid-nineteenth century about our very humble beginnings. Our beginnings have been rendered humbler still by paleontological revelations of the mindchilling length of tenure life has had on earth - 3.5 billion years so far as we know - and the equally numbing discovery of life's past and present variety. For this story to take root as part our most fundamental outlook may well take another century or two; for, despite the hyperactive fantasies some entertain of our present warp speed pace, our minds process no faster than they ever did, and our current ability to internalise and feel at home with the more radical conceptions of our great thinkers shows no indication of having outstripped the capacities of our predecessors. That we quickly get used to new gadgets is no sign of any matching capacity to absorb new science and philosophy.

As to internalising Darwin's tale, we only just yesterday began to get an inkling as to how life itself works. To internalise the tale requires not only that we acknowledge the common ancestry of all life on earth - something we pretty well do already - but also to imbibe it full strength, to identify our everyday actions in the world as flowing in part from it. If conceptions of a core human nature gave rise to a sense of our common human identity and thereby our common human worth, so conceptions of a core living nature should, when fully mature, transform our very sense of the worth of living beings.

Primitive signs of our trying to work out a new sense of our place in the Big Picture are not hard to find. Not only are we exploring with increasing confidence the 'naturalisation' of theories concerning human cognition, society, and history ${ }^{1}$; we are also beginning to speculate about what sorts of moral, social, and political principles and obligations might flow from naturalising our nature, so to speak, some of the first glimpses of which are to be caught in the

\footnotetext{
${ }^{1}$ The naturalising turn has not been without its critics. See for example, Stephen Stich, Deconstructing the Mind (Oxford University Press, 1996). My take on naturalising is, however, less finely focussed than Stich's who confines it largely to physicalism and the programme of physical reduction. The charge Stich addresses critically is this: if a phenomenon cannot be naturalised in that sense, it cannot be an object of serious scientific study, and so may be doomed to expulsion from any acceptable ontology. The sense I intend here involves our increasing acceptance of the increasingly broad explanatory role (waiting) to be played by the natural sciences regarding human nature. As we inexorably incorporate ourselves ever more deeply and inextricably into the Big Picture of time and life, we become increasingly less resistant to appeals to the Big Picture when we wish to focus upon our own kind. Whatever the fate of hard-core physicalism, any subsequent serious speculations about our nature can no longer dismiss or ignore broad evolutionary, genetic, and ecological influences.
} 
embryonic animal rights and green movements and the efforts towards shaping an ecologically and socially grounded environmental ethic. I would guess that, whatever the vicissitudes of such enterprises in the short term, we have reached a stage where we are no more able to revert seriously to pre- or anti-Darwinian conceptions than we are to revert to internalised acceptance of the divine right of kings or the inherent superiority of an hereditary aristocracy. Given that there's no looking back, we are in store for yet further transformations of our moral intuitions which will predictably shine new and probing lights upon our practices affecting the rest of the living world.

\subsection{Reflective Moralism}

The themes and undercurrents considered point to changes in outlook which might be most effectively explained as moral progress. I have emphasised the significance of the internalisation of this outlook which comes down to our reaching a state of conviction about certain things - the special worth of human life, for example, and eventually the special worth of life as such - which becomes so unassailable as to lead us unhesitatingly to revise any of our other beliefs and practices which may run afoul of them. But I don't wish to leave the impression that the sole success of moral progress is to make us unreflectively spontaneous in our new-found moral convictions. Certainly, such unreflective moral spontaneity contributes mightily to the effectiveness of new moral outlooks by relieving us of all doubt. There is, however, another unmistakable sign of moral progress, what one might call the ascendancy of reflective moralism. This consists in the warranted conviction that one's moral outlook is respectful of and maximally consistent with everything we can reasonably claim to know about human beings from the smallest to the biggest pictures we have available. Further, part of what a reflective moralism tells us is that when one becomes a person with personal surplus leisure, wealth, opportunity, the freedom to reflect - as may happen selectively in an aristocratic or more broadly in a liberal democratic capitalist culture, one is suitably in a position to assume reflectively the demands of an impersonal, self-consistent, impartial conception of trans-tribal morality, and then to try to respond in particular to the tensions it creates as real possibilities between living for oneself and one's allies on one's surplus and the real options of redistributing that surplus impartially in the form of active other-regarding conduct. For this is very much an opportunity - not a luxury at all - that arises for such surplus-laden beings, and opens the door for reflection on the real implications of informed altruism. One optimistic, however paradoxical, assessment of the point and value of personal and collective liberation from want 
and destitution is precisely to allow us to recognize and accept the increasing limitations upon our liberties, due in large part to an acknowledgment of an ever-increasing moral constituency, of a growing sphere of those who have genuine claims upon each and all of us.

In a nutshell, we progress morally by virtue of becoming ever more the kinds of beings for whom the demands of an impersonal morality both reflectively and spontaneously influence our personal and collective choices.

\section{Varieties of Progress}

What, then, is progress? I offer only a bare sketch of a cluster of notions, but these should suffice for present purposes. Any notion of progress typically involves some change of state, progress often being contrasted with stasis. ${ }^{2}$ Progress is a temporal notion and names a species of event. Concepts of progress differ primarily over the kind of change involved.

\subsection{Measuring Progress}

If progress names a type of change, any useful notion of progress must be operational; i.e. there must be determinable evidence, signs, and measures of progress. But because of the ways in which change may be manifested, there is nothing built generally into the notion which gives the edge to any given method of determination of change. So, to claim that progress cannot be spoken of with regard to some area of interest - science, morality, art, economy unless the change involved can be measured quantitatively would be question-begging. Why? Simply because quantitative measurement cannot proceed without the determination of units, and it is a contingent matter of methodological and empirical inquiry as to whether each domain in which progress may occur is fittingly and non-arbitrarily susceptible to characterisation in terms of standard units. While economic progress as such may appropriately be so quantified, it is highly doubtful that scientific progress, say, may be so measured. This is not to deny that we

\footnotetext{
${ }^{2}$ For present purposes, I ignore the question as to whether stasis can be a form of progress. This arises in the context of considerations of sustainability which is basically a form of holding things constant, the achievement of which may be regarded as progress in its own right. The achievement of sustainability, however, must itself involve a change of state. I also ignore cases where progress can be considered a (mere) return to a previous state after a period of decline or regress. This too, at any rate, involves a change of state. Whether true conservatism keeping things constant - can be progressive I reserve judgment on notwithstanding the moniker Progressive Conservative of one of Canada's major - however much in hiding these days - political parties.
} 
should attempt to seek such units where appropriate ${ }^{3}$, but one must nevertheless be prepared to give up the search if the only way to salvage one's units involves a patent distortion of the way a given domain changes. From this it is reasonable to assume that one must not privilege any notion of progress as more rigorous or objective than another just because it is measured quantitatively. That the concept of progress must be operational entails nothing about the modes of any measurement operations, nor does it entail that any one mode of measurement constitutes an ideal towards which all the others must aspire. More pointedly, there can be no warrant for the claim that non-quantitative measures are, for that reason, in themselves vague, loose or imprecise. This becomes pertinent in considerations of comparative progress we make, for example, between technological and political change.

To measure progress is be able to determine that progress has occurred. Should one also expect to be able to measure the degree and the rate of progress; i.e. by how much and how fast has progress occurred? Again, notions of degree and rate operate comfortably when one's measurements are quantitative. Still, degrees of change may be reckoned in a qualitatively scalar fashion without reference to base units, and all change rates are mapped against time which is typically measured in units.

\subsection{Neutral Progress}

I will give the name Neutral Progress to the sense of progress as mere change. This operates in expressions such as "charting the progress of $\mathrm{X}$ " where we identify nothing more than the course or progression of change in the form of a sequential narrative. We talk, for example, about the progress of a disease or a storm and mean nothing more by that than its sequential stages. Nor let us forget Hogarth’s A Harlot's Progress (1732/33). In this sense, everything may be said to progress. Note that neutral progress refers only to the changing thing itself. It is a property of all changing things that they neutrally progress.

\subsection{Teleological Progress}

Richer senses of progress involve more than mere change. The name Teleological Progress captures one special quality of change; namely, progress toward some end-state or goal G.

\footnotetext{
${ }^{3}$ See, for example, Larry Laudan's treatment of scientific progress in terms of counting solutions to puzzles in Progress and its Problems (Berkeley: University of California Press, 1977).
} 
Here we identify movement toward an end, some goal-seeking and goal-directed sequence of change. To capture fully the sense that there is something changing in a certain direction, we speak of the progress of $\boldsymbol{X}$ toward $\boldsymbol{G}$ where $\mathrm{X}$ is that which undergoes change on the way to some end-state G. Teleological progress refers to some future end-state which lies outside that which is changing. To refine the notion further, one must bear in mind that just as everything neutrally progresses, so many things teleologically progress just in case there is a programmed or pre-ordained sequence of changes they undergo. All living things, since they must die, progress toward death in this sense. Should a living thing fail to die, that would constitute a hitch in its teleological progress in exactly the same sense that a seed failing to germinate has had its progress impeded. In case that seems somewhat peculiar a view, consider the worry that cancer cells can be kept alive indefinitely. This is not meant to happen with living things. To speak operationally of teleological progress we assume that there exist patterned sequences of change which end with determinable and appropriate end-states. Teleological progress in this sense provides for reasonable expectation of outcome given that the programmed sequences of change are sure to result in the expected end-state, all things being equal. Such progress applies to many natural and artifactual processes.

Is all progress teleological progress? From the above, we call certain progressive changes teleological when we know what the end-state of the process is. The question is: can we call a progressive change teleological only if we know what the end-state of the process is? With well-documented highly regular sequences such as embryonic development or the smelting of iron from iron ore, we know full well where the processes are destined to lead, and can, accordingly, talk of very real problems in developmental progress when things are not as we reasonably anticipate. But there are many cases where we can at best only hypothesise that a sequence is teleological overall - for example, the development of technology or science perhaps only because it bears interesting and fruitful comparison with known teleological sequences, and we can thus hypothesise only very uncertainly as to what the end-state might possibly be. This is not to say that such progressive development is not teleological. It may well be for all we know. It is however to say that we certainly do not know whether such a sequence has a determinate end-state, and to ask what difference that might make.This question is linked to Hume's concern about particular cases of causation. For Hume, we are not entitled to say that some particular a caused $\mathbf{b}$ unless we have prior experience of As being regularly followed by Bs. By parity, I cannot say that a's progress is normal or impeded unless I already 
know how things of type A generally unfold. Again, I cannot, on this account, say that a has suffered a setback in its progress.

For now, we can draw a distinction between progressive sequences which are strongly teleological and weakly teleological. A progressive sequence is strongly teleological just in case we know it to be teleological. A progressive sequence is weakly teleological if, despite our not knowing whether it is teleological, we have some warrant for modelling it on a properly teleological sequence, that warrant being in part the explanatory and predictive advantage conferred by so modelling the sequence. In other words, a sequence is weakly teleological (merely) by being treated by hypothesis as if it were teleological.

It should be pretty clear that if we wish to talk at all about progress in any large areas of change - science, morality, politics, economy, technology, art, civilisation itself - we will at best be confined to talk about weak teleological progress. Why? Because we come up short on assurances as to where the progression is supposed to be heading, if anywhere. That we want it to be heading somewhere definite is another story. Here the end is not so much a matter of forecast as it is a matter of desire. We can thus make certain neutral progressions teleological. Such imposed teleological progress is typical of technology.

Equally clear is the fact that the operational mode for determining progress has no effect at all whether progress is weakly or strongly teleological. That the numbers-crazed astrologer takes the most careful and verifiable measurements of the movements of the stars and planets, and charts equally precisely their interrelations makes no difference to whether the romantic destiny in store for you as a result of such astral configurations is real or imaginary.

\subsection{Improvement or Ameliorative Progress}

Teleological progress conveys the importance of the patterned direction of progressive change. Further, it conveys a sense of normal development not merely as a predictable sequence, but, especially with many natural processes, as a characteristically law-governed sequence in the very nature of things, whatever our actual powers of prediction. All this considered, teleological progress conveys nothing about the beneficial value of that change. Let us call this value-laden sense Improvement or Ameliorative Progress, progress which is gainful change, 
betterment, advancement, and expressed in phrases like "making progress" or "a change for the better."

Whereas Neutral and Teleological forms of progress are uncontroversially part of the way things are, Improvement Progress is not. What counts as betterment or advancement seems a mere projection of our interests at a time - which themselves change. Indeed, Improvement progress is best characterised as change in $X$ which is gainful with respect to some interest $I$. That interest scarcely constitutes X's pre-programmed law-governed end-state, though it does reflect some desired goal regarding $\mathrm{X}$ for whoever has the interest.

Here teleology and improvement tend to get muddled. Millenarian and utopian views have abounded with expectations of the coming of the Messiah, the realisation of Absolute Spirit, the classless post-historical society, the one free fully international trading zone to name a few. For some, the process of natural evolution was set to reach its apotheosis in humankind. No doubt, there are latterday visionaries in science, business, politics, and art who posit some current in the core of the world which will carry us onward and upward. ${ }^{4}$ But note, these views of progress conflate two quite distinct ideas; namely, that some change is predictably directed toward an end, and that some change constitutes a positive advance. Highly-charged millenarian views are in fact Teleological-Improvement hybrids. They propose an ongoing advancement towards or convergence upon a superior pre-ordained end-state.

In summary, the Teleological variant specifies a law-governed goal- or target-relative relation whereby things in their relevant changes more closely approximate or converge upon some end. Importantly, this variant is future-drawn. There has been Teleological progress in $\mathrm{X}$ at time $t_{2}$ only if $X$ at $t_{2}$ is closer to (achieves better) some reasonably stable, acknowledged, and reasonably anticipated goal $G$ than $X$ at $t_{1}$ (where $t_{2}$ is more recent than $t_{1}$ ) when gauged against a goal common to both times. This presupposes a constancy of end-state over past and future times. The Improvement variant requires that things in their changes get better over time when compared with the past relative to some interest. Thus the Improvement view is backward-looking. There has been Improvement progress in $X$ at time $t_{2}$ only if $X$ at $t_{2}$ is better than $\mathrm{X}$ at $\mathrm{t}_{1}$ (where $\mathrm{t}_{2}$ is more recent than $\mathrm{t}_{1}$ ) when gauged against standards of goodness

\footnotetext{
${ }^{4}$ On the other side, there have been warnings of ultimate regress - a replacement for stasis as the contrast with progress - as changes are all for the worse.
} 
(norms) relating to $\mathrm{X}$ common to both times. This presupposes a norm constancy over present and past times. Otherwise there is stasis or regress.

What exactly is the relationship, if any, between the Teleological and Ameliorative conceptions of progress? Teleological progress does not entail Improvement progress. Neither does Improvement progress entail Teleological progress. Why not? Because it may be the case that (a) goals and interests are not fixed and in fact change over time so at best one would have a kind of truncated convergence (no overarching long-term goals or direction); and (b), more seriously, there may in fact be no end-state upon which the changes converge whatever the stated interests may happen to be. For all we know, there may be no final truth about things in science or ultimate fairness in law or ultimate control in technology. All considered, however, in order for us to understand properly what is at stake in talking about progress in large practise domains such as science or morality, we need somehow to link the Teleological and Ameliorative or Improvement views. This may be possible by drawing yet another distinction between internal and external progress, sketched below.

\section{Progress Hierarchically Conceived}

\subsection{The Relativity of Progress}

In considering progress in the human sphere we leave behind the relatively stable reality of natural ends. Nature sets its developmental norms which are stamped into the program of life. ${ }^{5}$ We have become quite good at exploiting these when we use nature to further our own interests. But human ends are a thing apart and subject to the vagaries of human will and desire. What counts as progress, we are often reminded, is in the eye of the beholder. There is no progress but for the realisation of the interests of those concerned. Once desired goals and variable conceptions of gainfulness enter the picture, we face, so it seems, the dissolution of progress - at least anything that can be counted impersonally by that name. If human progress is thus relative to the interests of those in charge for the time being, talk of progress is simply the selective biography of will, and so of no special moment in the real history of the earth.

\footnotetext{
${ }^{5}$ We seem to have abandoned any notion of teleological progress in the overall development of the non-living domain. At least, historical geology rests on no such principle even if it may identify regular sequences of largescale change. Of note here is that no such discovered geological sequence embodies any norms of change; i.e. a predictable sequence is not at the same time a proper sequence. That said, there certainly seem to be normative elements built into our identification of a great many abiotic sequences; e.g. many chemical and mechanical reactions, and upon these we rest our technology.
} 
Examples of the relativity in human progress are common. Progress in one domain may constitute regress in another. Consider the development of Cyclone B gas by the chemical giant I.G. Farben for use in the German death camps. Technological progress in the development and deployment of deadly weapons or the most cost-effective means of disposing of minorities, say, may reasonably be seen as regressive with regard to the pursuit of moral or political progress. Moral progress reckoned in terms of the protection of wilderness or the emancipation of the enslaved may constitute regress in the economic domain. (I ignore here optimistic claims meant to assure us that all is 'win-win', that we can have our cake and eat it too. In most cases, there is simply no evidence to this effect because we cannot predict the future of complex events with any reasonable betting odds. Anyway, progress domain clashes are not like business deals, corporate mergers. More sensible is the view that we are stuck with trade-offs.) Political progress in the form of expanded democratic participation may scuttle scientific progress where that depends upon complete independence of inquiry. Witness the growing public uneasiness about the drift of genetic research. And on it goes. This all happens because of the free-floating conception of improvement and the lack of substance to any overarching teleological plan for the direction of human culture.

We are not, however, doomed to this frantic emptiness. At least, we can order our interests hierarchically and identify overarching quasi-teleological end-states which take the form, not of definitive and final states of affairs (about which we can only fantasise), but of definitive constraints upon our collective pursuits. In a hierarchical notion of progress, the ends of any one level are subject to the constraints placed upon them by the ends of the next-higher level. This is especially so if all dimensions of progressive change are themselves meant to converge upon what we might call Ultimate Benefit. Supposing we can talk meaningfully about progress in science, government, morality, business, and so forth, it should also be possible to talk about progress in all these dimensions converging upon a common end. At least, such would be the plan if we viewed these domains as each occupying a role in the development of culture or civilisation or humanity itself. However foolishly grand this overarching notion may sound, the localised and domain-specific alternatives promise very little. For, outside of any such comprehensive framework, we are bound to ceaselessly and screamingly arbitrary enterprises.

Claims of forward-looking Teleological progress, when approached as isolated sequences, cannot, by themselves, anticipate regressive effects upon other teleological streams. 
Considerations of backward-looking Improvement progress, by themselves, imply no direction toward or convergence upon some independently valuable end-state. Taken as a cluster and conceived as independent practises, progressive streams collectively converge upon nothing in particular, nor are we justified in believing it likely that all independently achieved improvements will constitute any sort of aggregate improvement.

To give some body to this notion, a rough analogy can be drawn here with technological progress in the development, say, of a machine like the internal combustion engine or the personal computer. The functional components of any machine will themselves undergo progressive change. We can, for instance, consider developments in the parts of engines such as carburettors or cooling systems which, though undertaken in relative isolation, collectively contribute to progress in the overall engine itself. But it may not always work out so well. Increased efficiency in the cooling system may result in a decrease in the amount of power the engine can deliver to the drive train. An overarching conception of progress in the development of the entire machine is required to ensure that progressive improvements in lower-level components are compatible with a conception of the machine's teleological progress.

\subsection{Internal and External Progress}

Above, we were beset by the rampant relativity occasioned both by the improvement and teleological views of progress which oblige us counter-intuitively to speak in equal terms about progress in the development of weapons of mass destruction and progress in the development of life-saving medication. To avoid this, we either can (a) deny outright that there can be progress in such things as mass destruction, or (b) identify at least two distinct levels of progress. Option (a) seems implausible given the cogency of the improvement view. Our nastiest weapons are unquestionably better than their predecessors. Option (b) seems more fruitful, and calls upon a further distinction; namely, progress internal to a practice and the progressiveness of a practice itself or external progress for short. ${ }^{6}$ This division will work

\footnotetext{
${ }^{6}$ I am using the term 'practice' rather broadly here in the sense not unlike that introduced by Alasdair Macintyre in After Virtue (University of Notre Dame Press, 1981). Under practices are included not only those specific organised rule-bound goal-directed enterprises called 'techné' which has loosely been translated as 'craft' (examples of which include the skills of the doctor, cook, lawyer, navigator, engineer, and, for Plato, politician), but also broader superordinate social institutional categories such as law, government, morality, science and technology, trade and business, religion, art and the like within which many of the various crafts may be identified.
} 
best if the improvement view were somehow subordinate to some higher-order teleological or convergence view. So, whereas any practice has its own internal projects and development, and the prospect of retrospective improvement with respect to these, it would not follow that making progress in that internal respect contributed to progress in another, superordinate, respect. If great technological progress were made in some area of practice (weapons design, say) which either contributed directly to ends which were blatantly destructive of life or which left in its wake a number of destructive however unintended side-effects, one might be inclined to say that such internal progress is progress by courtesy. Why? Because, there is another test which must be met if some change is fully progressive. Note that this notion describes the progressiveness of whole practices (e.g. weapons development, animal husbandry, guitarmaking, advertising, etc., and, more broadly, science, art, government, business) as opposed to progress within a practice.

In brief, a practice is fully progressive only if it makes external progress. This comes down to saying that not all practices and the progress they achieve are to be viewed in the same terms. So long as any practice may be judged both internally and externally for progress, there must be first- and second-order practices, or subordinate and superordinate practices. For a first-order practice to be fully progressive, it must be progressive with respect to some secondorder practice. Otherwise, it is merely internally progressive. One could argue that Morality occupies the role of the standing superordinate practice, particularly where some internal progress comes into conflict with it. This makes all the more sense if we can conceive of Morality as being convergent upon some common end, or, at least, which subjects all subordinate practices to some common convergent constraint. What, after all, could be the end of weapons research? Surely, not to develop weapons which could kill everyone.

It needs saying at the outset that the premium source of such quasi-teleological constraints derive from morality. Why? Because of all the large domains in which we believe progress to be possible, morality offers not only an opportunity to measure improvement by retrospection, but offers as well reasonably clear quasi-teleological ends in the form of determinate and absolute constraints. Though science and technology at present may retrospectively be better than science and technology past, no one can say at all clearly upon what all this improvement is meant to converge. ${ }^{7}$ That is because, without having the whole truth to hand, we have no

\footnotetext{
${ }^{7}$ That said, the belief that science has an ultimate and inevitable point of convergence is a theme running through the scientific realism of Charles Sanders Peirce and others. As Peirce puts it:
}

[A]s each [investigator] perfects his method and his processes, the results will move steadily toward a destined center. So with scientific research. Different minds may set out with the most antagonistic 
way of knowing how much closer we are to it now than we were before. By comparison with our conception of the ultimate future of science, there seems to be a sheer vacuum in the area of economic progress which seems totally, anarchically and perhaps inevitably dominated by a retrospective view, by considerations of relative improvement over the past gauged limitedly in terms of indicators like aggregate output. Science looks to the final truth about things; technology to the ultimate control over natural processes. Upon what is economic activity meant finally to converge? Indefinitely increasing material wealth, all things being equal? But things are never equal in that respect. Morality occupies a special role in all this because its ends are human-driven ideals. In their 'ideality', they are very much more real to us, more palpable and determinable than any conception we might have of what the Whole Truth about Nature might be like. Though there may be a whole truth about nature, there may not; but even if there were, we cannot begin to imagine what it might be like. And so for ultimate control over nature, the aim of technology, which, of course, rests on the whole truth. If there is any comprehensive Teleological-Improvement hybrid at all, it is morality.

To see why morality is privileged in this regard, one must have a sense that, ultimately, there cannot be any point in our specific enterprises unless there is some over-arching point to all our enterprises as such. Such a conception of the ultimate superordinate focus is characterised by Alasdair Macintyre as the search for "the good life" about which he says:

views, but the progress of investigation carries them by a force outside of themselves to one and the same conclusion ... The opinion which is fated to be ultimately agreed to by all who investigate is what we mean by the truth, and the object represented in this opinion is the real.

Charles Sanders Peirce, "How to Make Our Ideas Clear" in Philip P. Wiener (ed), Charles S. Peirce: Selected Writings (New York: Dover Publications, 1966): 133 (my italics). See also W.F. Sellars, Science, Perception and Reality (London: Routledge and Kegan Paul, 1963): 96-7. Relatedly, an historically sensitive treatment of science as a practice structured to reach, regulate, and sustain community consensus practice is explored by Philip Kitcher, The Advancement of Science (New York: Oxford University Press, 1993). Further treatments of convergence are found in Richard Boyd, "Realism, Underdetermination, and a Causal Theory of Evidence", Nous 7 (1973): 1-12; Richard Boyd, "On the Current Status of Scientific Realism", Erkenntnis 19 (1983): 45-90; and Hilary Putnam, Meaning and the Moral Sciences (London: Routledge and Kegan Paul, 1978). Similar in spirit if not in mood is the non-ending effort humans exercise in trying to rise to the next level of objectivity, the one yet preparatory for the ever-receding horizon of objectivities before us. See Thomas Nagel, The View from Nowhere (New York: Oxford University Press, 1987). Convergentism does not lack its critics. Besides the relentless assaults from Kuhn, The Structure of Scientific Revolutions (University of Chicago Press, 1970); Feyerabend, Against Method (London: Verso Books, 1988); and defenders of "the strong programme"(e.g. , Barry Barnes, David Bloor \& John Henry, Scientific Knowledge: A Sociological Analysis (London: Athlone Press, 1996); see Larry Laudan, "A Confutation of Convergent Realism", Philosophy of Science 48 (1981): 19-48. 
....the good life for man is the life spent seeking for the good life for man, and the virtues necessary for the seeking are those which will enable us to understand what more and what else the good life for man is... ${ }^{8}$

Of course, one needs not only those virtues which enable us to understand what the good life is, but also a social and political system in which those with such virtues may exercise them fully in such a way as to be most likely to reach an answer. The mere having of such virtues is not enough. One must also have the opportunity to exercise them, and that depends upon the kind of community in which one lives. Analogously, moral progress - the movement toward moral improvement and morally worthy ends - is possible only in a social and political setting which provides an environment in which the pursuit and realisation of such morally worthy ends is conceivable. Couple this with the constraints imposed both by our tradition of liberation and our beginning to uncover the real roots of our nature, and we invariably find ourselves increasingly less prone to accept the internal successes of subordinate practices on their own terms.

\section{Taking Stock}

We have, so far, covered a fair amount of ground, and an interim summary is in order. Regarding human activities, most of what is called progress turns out unsurprisingly to be relative to specific practices. Progress in a practice conceived in isolation can be viewed either teleologically as movement towards an identifiable known end-point which constitutes the ultimate goal of the practice, or in an ameliorative sense where, without any clear conception of where the sequence is meant finally to go, we judge our present state to be an improvement over the past. So we count progress in terms such as these: we are now less prone to die from childhood disease than we once were; we now can produce more food per hectare than we once could; we now understand more about the history and mechanism of life than we once did; we now enjoy a greater per capita income than we once did; and so on. In each case we can talk sensibly about amelioration in the practice, and yet we cannot talk comfortably about amelioration generally. For our progress has been completely indiscriminate. How so? Because of the following: we are now better able to kill and maim than we were in the past, better able to reduce the number of species than ever before, better able to increase the human population than ever before, and so on.

\footnotetext{
${ }^{8}$ Alasdair Macintyre, After Virtue (Notre Dame University Press, 1981).
} 
All of these represent some kind of advancement over past practice, and, relative to one view or another, all constitute progress. But we reach a peculiarly awkward state. If we merely relativise progress to given desires and local achievements, and if we accept the enormous variety of desires afoot, we are forced to accept that progress in one area constitutes regress in another, and thus forced to think of progress as merely relative to local interests. If it is merely relative to local interests, there is no neutral sense we can attach to the notion at all. Now, we may wish to deny any such neutral sense altogether. If so, we are perfectly free to carry on accepting that progress as such is (merely) a name attached to certain local interests and desires. The value in this, if nothing else, would be a variety of intellectual honesty in which we decide simply to stop talking glamorised nonsense about our movement onward and upward. Whose movement onward, after all? What direction upward, after all?

But we are not doomed to accept that any notion of progress must founder upon such relativity so long as it seems sensible to claim that some progress is just bad or over-rated, and that some progress is on the right track. Suppose we appeal generally and neutrally to a 'right track'. Surely this is exactly what we are doing when we question, say, the green revolution's legacy of soil contaminants, or the tendency of growing multinational domination of world trade to emasculate government for and by the people. Suppose such an appeal makes sense - and it must make at least as much sense as any conception we might have of a bad law for, contrary to the fantasies of legislators, the law is not always the Law. Then we have somehow to stand outside the local domains of teleological and ameliorative progress and ask how these fit together and collectively contribute toward some higher-order end. At that point, we acknowledge the need to distinguish between internal or localised progress, and external or superordinate progress. From that external standpoint, we require something at least quasiteleological; i.e. we need a sense that all our varied practices must converge upon some superordinate focus.

What that focus is is no easy task to state clearly, but we are not entirely at a loss. We have, as outlined at the start, a long-standing and continuing tradition of philosophical inquiry into the foundations of human value. That has given rise to a culture which has begun to accept and internalise the fundamental values of autonomy and sovereignty. These give us, if nothing else, a very grand set of external constraints upon our subordinate practices. And these constraints have palpably affected the very development, structure, and reform of government. 
Sadly, as government slowly accepts its limitations, we are beset by the regressive growth of so-called managerial or corporate culture which too will eventually find its proper place once response to the constraints it tends to ignore have been made. Change in our scientific understanding of nature has brought us - perhaps inadvertently - ever more into the very picture of the world we find ourselves forced to draw. From the simple and direct Baconian imperative to better the human estate, science moves slowly, perhaps begrudgingly, to hear a richer imperative - to understand just where we fit in the bigger picture and just who we collectively are. And as our own story begins to blend within the bigger picture, we are increasingly constrained in our conception of our overall worth. Consider, in that respect, the implications for our regarding ourselves simply as inhabitants, temporally limited, come here by chance. Both these outlooks are unmitigatedly moral since both reflect very generally upon what, for the sake of the beings involved, we may and may nor rightly do.

Our occasional and (thankfully) unkillable flair for intellectual consistency does the rest. Such, at least, I read without, I hope, excessive optimism in the many diversity respecting initiatives of concern at present - about species, minorities, ethnic groups, languages, ecosystems, national sovereignty and more - which take fragmentation and difference as ultimate. And which take the preservation of fragmentation and difference as the prime constraining imperative as flowing from what we have learned over the last several centuries.

\subsection{Where All This is Tending}

I began with the antics of Jake and Elwood to provide a simple indication of what moral progress, as external to our local limited enterprises, looks like on the ground. I take it to be a sign of moral progress not only because of its ameliorative tone, but also because it points to a teleological drift. Why don't we buy and sell each other? Is it good for business? At one point it was a disaster for business, but we learned to accommodate that. Is it good for science and technology? Absolutely not, for it stifles our efforts to understand fully and to control. Somehow, miraculously perhaps, something besides local limited progress prevailed.

Is this the end of that story? I think not, if I can permit myself the treat of cautious projection. The Jake-Elwood joke is possible only because of a gradual hard-fought move towards increasing inclusive moral expansionism. The story of the 'expanding circle' has been our 
history overall, and such, looking at certain developments, seems an entrenched theme. It takes two primary forms; namely (a) growing moral Inclusiveness, and (b) growing moral Pluralism.

The former reflects the growth of subject-specific moral developments which has cast its net over women, children, foreigners, humans, other animals, life, the ecosphere, and is aimed to capture common due and proper moral regard, to ensure inclusion in the class of morally considerable beings and, ultimately, to achieve moral equality. The latter reflects the growth of subject-specific moral developments designed to locate and emphasize the moral relevance of difference and the regard needing to be shown to it. Push these where they lead and the limits to our internal progress become ever greater.

But, surely, one will be overwhelmed by doubt, by pessimism about moral progress. How can we square any belief in moral progress with the barbaric facts of the century, the many purges, acts of genocide, brutal governments, and other forms of oppression? What indeed of the mass decimation of habitat, the wholesale extermination of other species in the name of economic gain? Where in all this does one situate the seeming trend toward greater moral inclusiveness?

On this, just two parting reflections. It is a sign of general moral expansionist sentiments that an increasingly larger proportion of people are at least now aware that certain actions taken actually have a moral quality, that they are not merely to be rued and abided fatalistically, that there is a moral reckoning which must be taken into account. There are even signs of institutional acknowledgment; at least, such is one take on the Nuremberg Trials, the various War Crimes Tribunals, Environmental Reviews, the International Whaling Commission, and more. Law, which lays out our most commonly acknowledged form of constraint, has been changed by straightforward moral demands for change. The second remark derives from some made earlier on about time and belief. Over the long run, we now present will indeed all be dead. But such is the pace of real and significant change in human history and understanding that we can, perhaps at best, be aware, given the story lived by our own dead predecessors, that the story has indeed changed, and changed intelligibly. Where we have perhaps progressed most is in appreciating the presence of a larger scale dimension of progressive change in human civilisation which has let us sense the force of something daunting yet oddly agreeable in its development. And with that the reflection that there is something altogether provincial and even immature in attaching any interest in the fact that, yes, over the long run, we now present will indeed all be dead. Thank heavens for that, one should say. Think otherwise of the places others next in line would never have seen. 